\title{
En Bloc Peritonectomy Specimen in a Case of Ovarian Cancer
}

Richi Khandelwal ${ }^{1}$, Manoranjan Mahapatra ${ }^{2}$, Jita Parija ${ }^{3}$, Agniv Sarkar ${ }^{4}$, Smruti S Pattnaik $^{5}$

\begin{abstract}
This is a picture showing en bloc peritonectomy specimen during primary cytoreduction on a case of ovarian cancer. Keywords: Adjuvant chemotherapy, Epithelial ovarian cancer, Peritonectomy. Journal of South Asian Federation of Obstetrics and Gynaecology (2021): 10.5005/jp-journals-10006-1924
\end{abstract}

The picture shows peritonectomy (pelvic, abdominal, and diaphragmatic stripping) along with the ovarian mass, uterus, and contralateral adnexa removed en bloc with appendix, omentum, para-aortic lymph node, and part of Glisson's capsule.

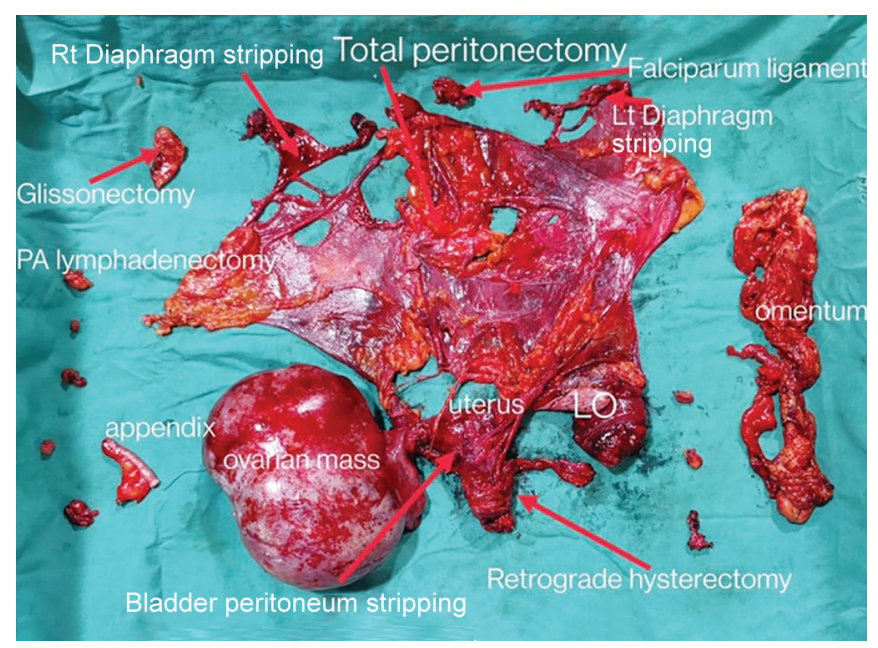

${ }^{1-5}$ Department of Gynecological Oncology, Acharya Harihar Post Graduate Institute of Cancer, Cuttack, Odisha, India

Corresponding Author: Richi Khandelwal, Department of Gynecological Oncology, Acharya Harihar Post Graduate Institute of Cancer, Cuttack, Odisha, India, Phone: +91 9785077004, e-mail: richi_kh @yahoo.com

How to cite this article: Khandelwal R, Mahapatra M, Parija J, et al. En Bloc Peritonectomy Specimen in a Case of Ovarian Cancer. J South Asian Feder Obst Gynae 2021;13(4):277.

Source of support: Nil

Conflict of interest: None

() The Author(s). 2021 Open Access This article is distributed under the terms of the Creative Commons Attribution 4.0 International License (https://creativecommons. org/licenses/by-nc/4.0/), which permits unrestricted use, distribution, and non-commercial reproduction in any medium, provided you give appropriate credit to the original author(s) and the source, provide a link to the Creative Commons license, and indicate if changes were made. The Creative Commons Public Domain Dedication waiver (http://creativecommons.org/publicdomain/zero/1.0/) applies to the data made available in this article, unless otherwise stated. 